\title{
Probe into the Nature and Design Principles of Surface Vessel Disposition
}

\author{
Feng Tian \\ Department of Surface Ship Command, Dalian Naval Academy, Dalian, 116018, China \\ 285892287@qq.com
}

Keywords: Surface vessel disposition; Operational elements

\begin{abstract}
The general quarters of surface vessels is a kind of unique surface organizational form. This paper analyzes the essence of surface vessel disposition and the relationship with operational elements, and puts forward the basic idea of surface vessel disposition design, which provides a theoretical basis for the design and disposition of new surface vessels.
\end{abstract}

\section{Introduction}

The general quarters of surface vessels is a kind of unique surface organizational form, which refers to the configuration and provisions of surface vessels in order to meet the needs of combat or daily work and to establish the positions and responsibilities of all crew members. By nature, there are combat disposition and daily disposition; according to the scope, there is a whole-ship disposition and departmental disposition. The purpose is to combine the crew members with weaponry and equipment and with technical equipment so as to ensure that the warships promptly and accurately and in an intense and orderly manner exercise their war-time peacetime under the unified command in order to give full play to the overall effectiveness of the warship. In essence, the disposition of warships is also an organization. The difference is that warship disposition is an organization with specific tasks under the warship organization. It more emphasizes the mission characteristics. The tasks may be combat tasks or may be routine tasks. It can be said that no specific task will not have disposition of the organization, the disposition is for a specific task organization.

\section{The Essence of the Disposition of Surface Ships}

The disposition is task-driven, and the effective organization of people (preparation) and equipment for the implementation of a specific task is to maximize the effectiveness of the task. In short, man-machine, the task of a high degree of harmony. Disposition is usually used for multitasking organizations (such as ships), and it is implemented on a mission-organized organization or platform (such as Army tanks or Air Force aircraft) rather than using disposition. Instead, the organization is implemented using a staff-organized organizational model Or platform operation. Therefore, disposition is a temporary task-organizing model of a man-machine system (such as a ship or a typical large-scale man-machine system) that is given a multi-mission when performing a specific task. It is task-driven to compile and equipment as the basis, to maximize the effectiveness of the goal.

Mission is the disposition of traction, what mission need to develop what kind of disposition, different disposition for different tasks, there is no "all-round disposition" for all tasks. Because the concept of disposition applies only to diverse task organizations, and different tasks require different dispositions, it is common for organizations to deploy in the same organization (platform) in many forms of organization. Take a typical destroyers as an example, its tasks can be divided into two categories: combat missions and daily operational missions. Combat missions include self-defense operations, combat readiness, damage control, anti-terrorism, anti-nuclear, chemical prevention, Maritime inspection catch and other disposition. Routine operation tasks include: occupying the palm of your hand, cleaning, mechanical inspection, anchoring, docked, life-saving boats, dinghy, sailing, flying in fog, carrier-based aircraft taking off and landing operations, , Water, ammunition, supplies) disposition, anti-typhoon disposition. 


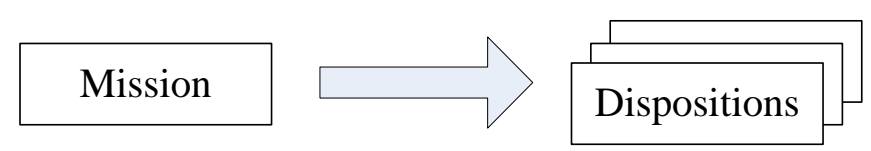

Figure 1. The relationship between disposition and mission

\section{Disposition and Staffing}

Staffing is an organizational form designed by the department to meet the operational needs of the system and equipment, and is usually marshaled on a professional basis. Staffing is the "pool" of disposition, or the constraint of disposition. That is, disposition must obtain human resources from staffing and meet the needs of mission execution through the reorganization of human resources. In theory, staffing is enough to meet the needs of disposition. However, in practice, especially when the new equipment is facing new mission requirements, the human resource needs of disposition are not met due to the lack of a running-in process among the three.
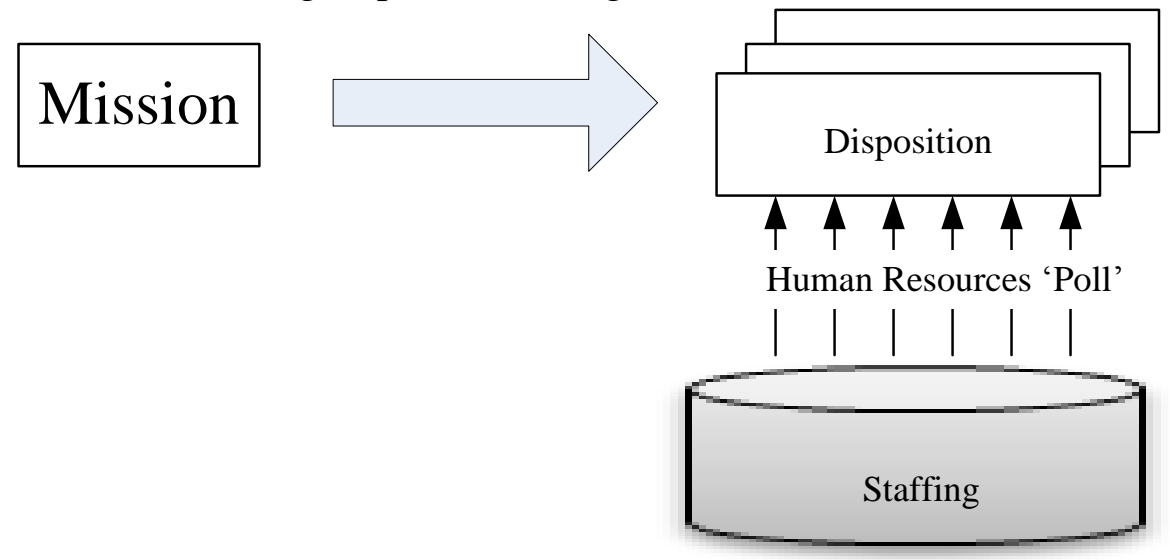

Figure 2. The relationship between disposition and staffing

When the initial establishment can not meet the disposition of human resources requirements (such as the establishment of new equipment post), the design of the disposition often put forward extra-preparation requirements for the preparation, resulting in the preparation of the adjustment. Therefore, the new equipment is often formulated in the form of interim preparation plus maneuver, so as to redeploy the post according to the disposition needs after the disposition research is drafted. However, the disposition of the new equipment needs to be determined by a process, which leads to the establishment of definite needs and Disposition repeated many times to adapt to each other. In this sense, the relationship between disposition and compilation is reciprocal and iteratively iteratively revised.

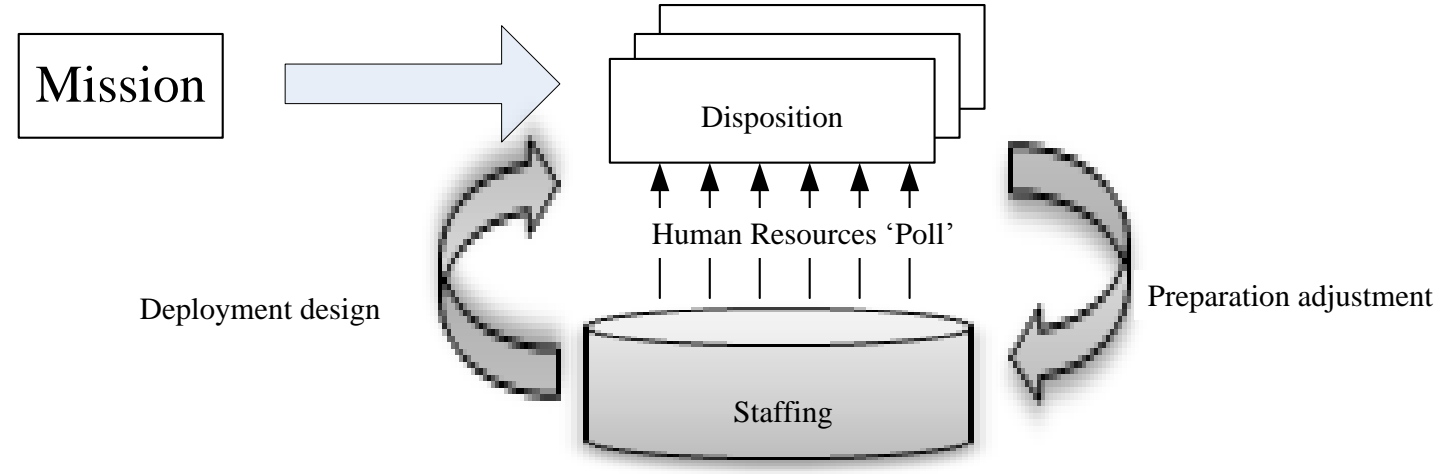

Figure 3. The relationship between the disposition of new type of vessels and staffing 


\section{Disposition and Equipment}

Equipment is the means to perform the task tool, is deployed by virtue of. Deployed through the positioning of personnel to achieve the effective use of equipment, so as to achieve the best mission performance. Therefore, equipment is an indirect basis for disposition and is based on a tool used to maximize the effectiveness of a task. Driven by the mission, the integration of equipment and human resources is achieved, that is, the man-machine integrated operation mode is achieved and is the best disposition.

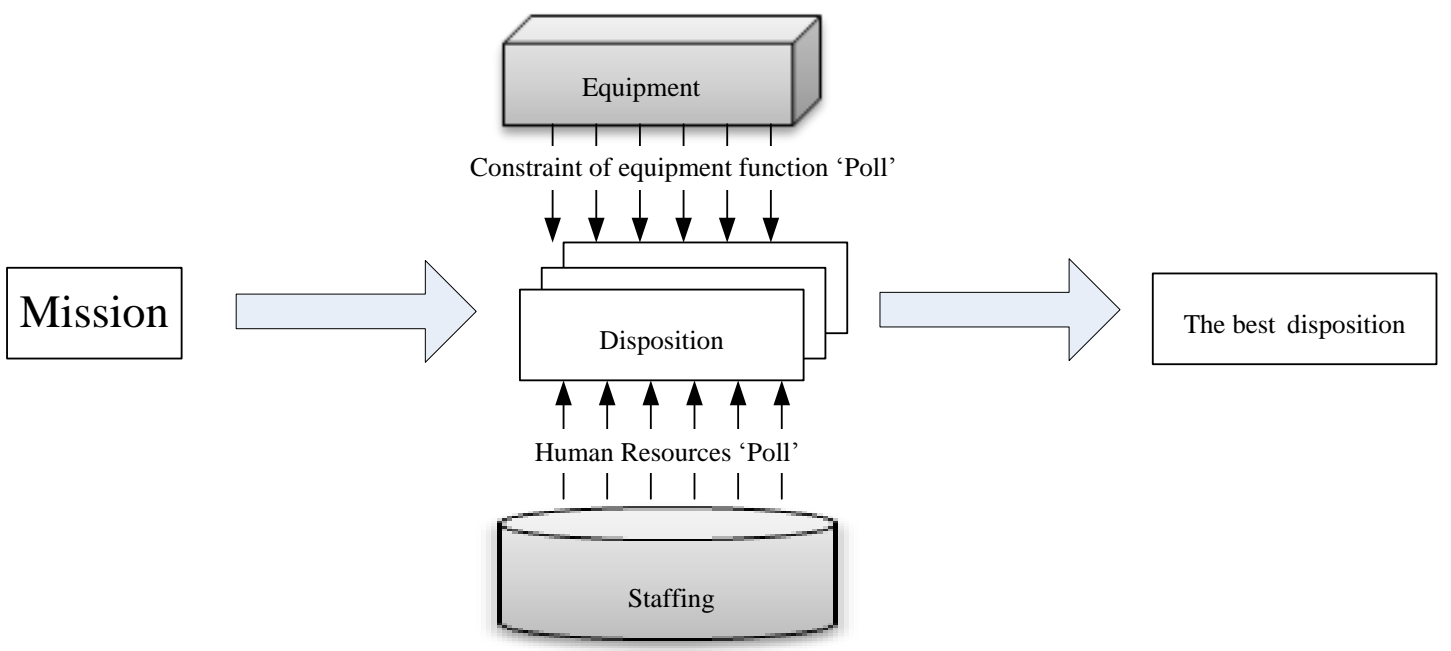

Figure 4. The relationship between the disposition of new type of vessels and equipment

\section{Disposition and Process}

Process is the use of equipment to perform mission sequence of activities. The process is derived from the decomposition of the activities of mission. Mission are usually general and approximate. They need to be further decomposed and refined into activities that can be executed by combat positions. Taking the combat of air combat as an example, the task can be decomposed into "remote warnings" "Remote interception", "regional interception", "short-range interception", "end of the fight against air" and other series of activities, there is interdependence between these activities, by the decomposition of activities and the relationship between the activities of the sequence For the process, air combat operations as an example, the association between the activities of "remote warning" - "Remote Intercept" - "regional intercept" - "short-range intercept" - "end of the fight against the air." Process is the specific basis for the design of the disposition.

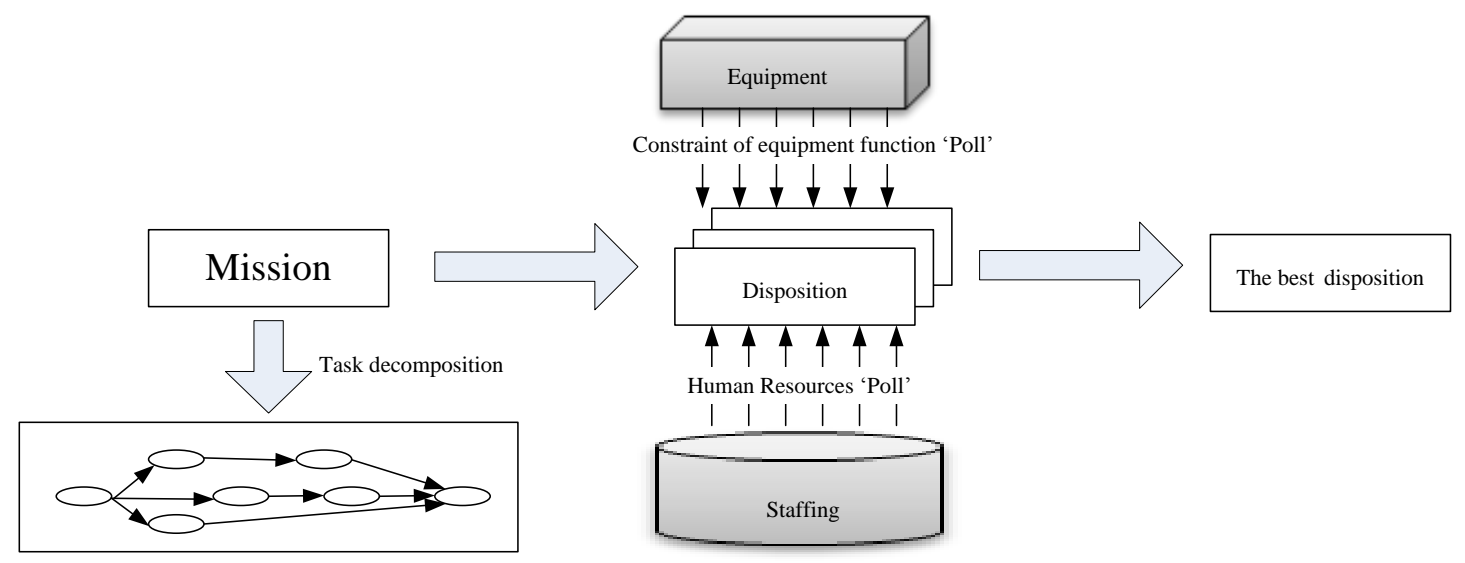

Figure 5. The relationship between the disposition and process 


\section{Disposition and Command Relationship}

The command relationship is the relationship between the warfare positions and the center war positions formed during the design and disposition of the disposition to improve the operational efficiency of the disposition. The command relationship is different from the administrative relationship, and the administrative relationship is the relationship between administrative agencies and administrative posts that are set up to facilitate daily administration. The command relationship originates from the arrangement of disposition posts and is the relationship between the battle positions set for the effective organization of the war positions in disposition. It is embodied as the center war position, the mission command position, and the relationship between the war positions and positions . Command and control is the core element of disposition design.

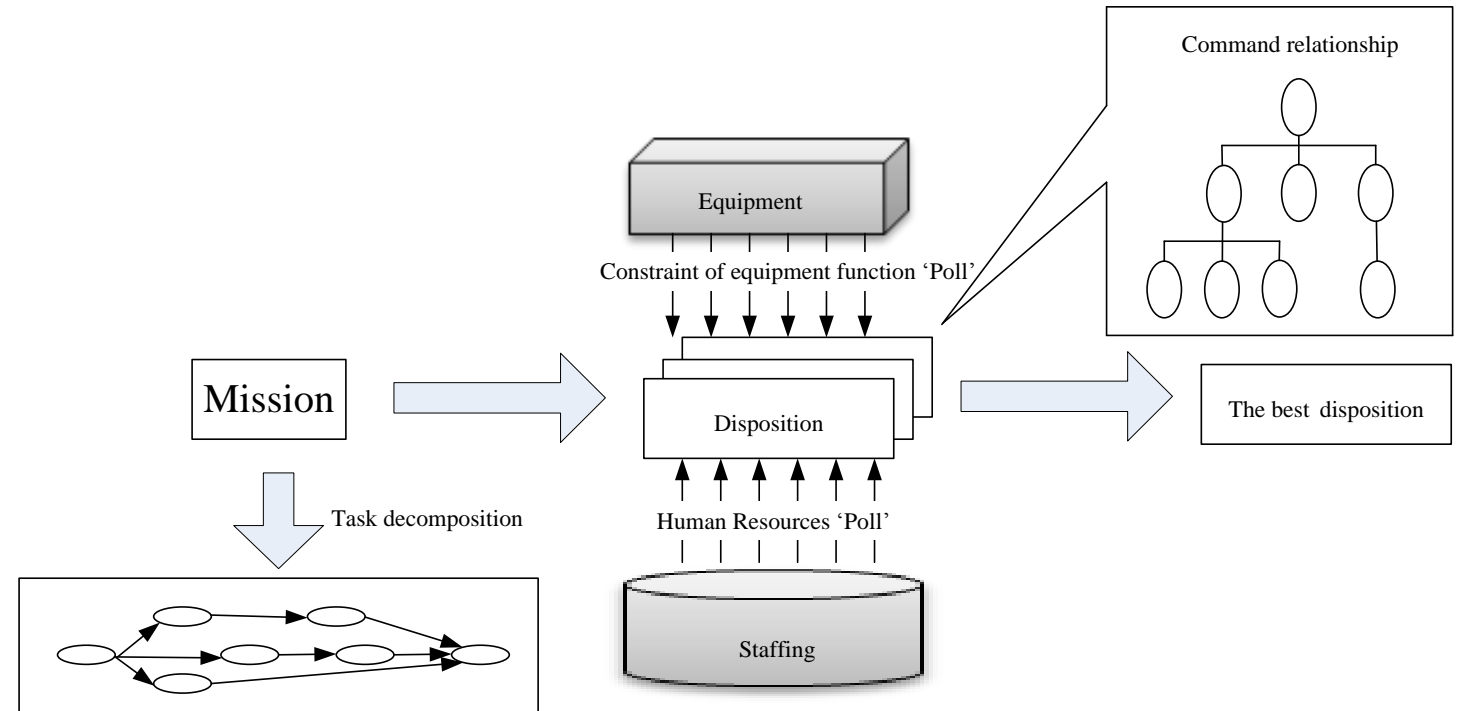

Figure 6. The relationship between the disposition and command relationship

\section{Disposition Design Principles}

According to the above analysis, we can see that the design of the disposition is based on the mission as the driving force, the staffing constraints and the equipment as the means to set the reasonable position, the job responsibilities and the relationship between the positions in order to maximize the effectiveness of the mission. In short, the specific tasks through the scientific design of the integration of people and equipment, to achieve the goal of efficient man-machine system operation. In essence, the disposition of design is a kind of organizational design, the goal is to maximize the effectiveness of mission, the constraints are the preparation of posts and equipment, the design principle as shown below.

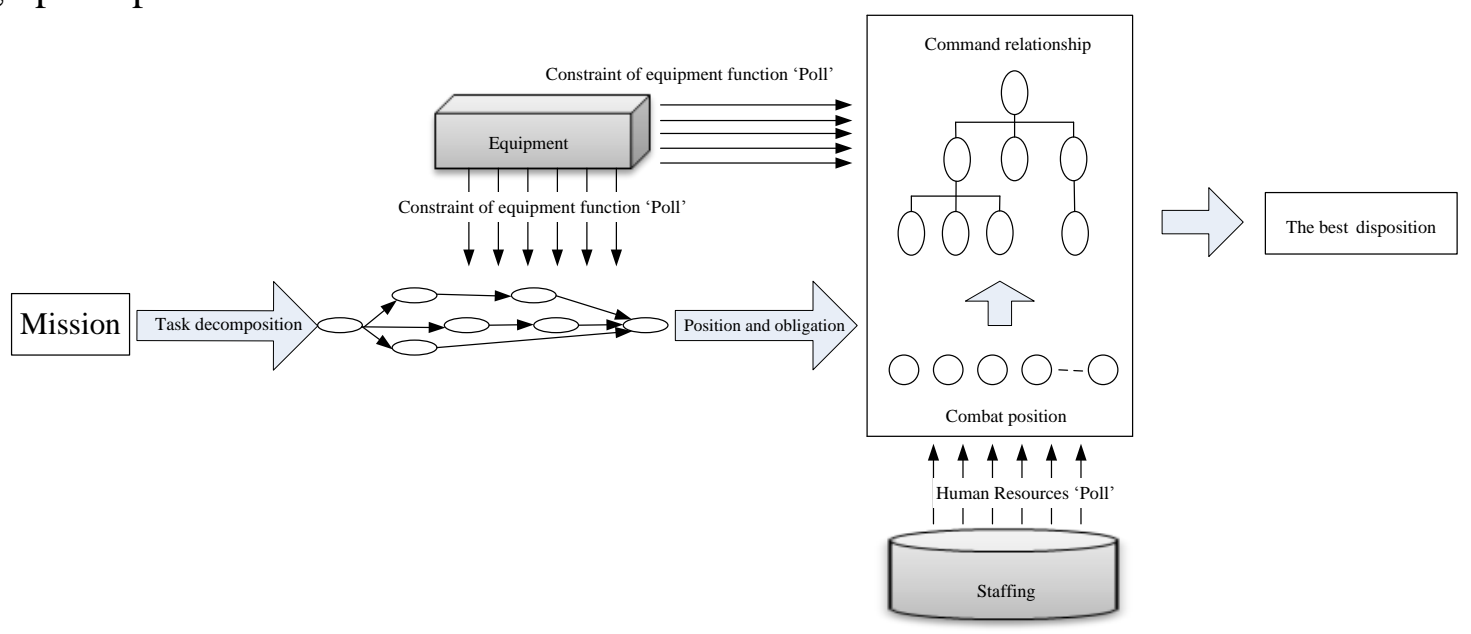

Figure 7. The relationship between the disposition design principles 
Disposition design is mainly based on three aspects: First, the equipment, that is, man-machine system to perform mission rely on equipment; Second, staffing, usually based on equipment design staffing will be given an initial operational staffing plan, In the disposition of the design is completed, and after the test of practice and then staffing accurate positioning: Third, endow human-machine system mission. Three conditions are the necessary conditions for the disposition of design, are indispensable.

Disposition is essentially the realization of man-machine system to achieve efficient operation, how to achieve efficient man-machine system operation? The key problems to be solved are twofold: First, the scientific processes, processes, or procedures that a man-machine system performs its mission and performs its tasks are the basis for the disposition design. It is similar to the process of one product, with fewer steps or incorrect logical order, Will lead to defective or non-finished products appear; Second, according to the process to establish its corresponding war and center war position, also said to be the organization and management agencies, is responsible for the operation of the process and supervision; The third is to clarify the relationship between the various combat positions and the center combat position and establish the relationship of command, control and cooperation so that the task flow has the necessary communication and communication channels in the process of implementation. The whole system has commonality in the process of task adjustment or process reorganization goal, be able to react quickly and avoid crisis.

\section{Conclusion}

The disposition of surface vessel is a direct tool for operations management and plays a very important and fundamental role in effectively carrying out combat missions. Studying the essence of surface vessel disposition, the relationship between surface vessel disposition and operational factors, and the basic principles of disposition design are very important for improving the operational effectiveness of surface vessels.

\section{References}

[1] Lu Hui, Dong Zai-wang. Carrier frequency offset estimation for DAB receiver based on phase reference symbol[J]. IEEE Transactions on Consumer Electronics, 2000, 46(1): 127-130

[2] Criado R, Flores J. Herandez-Bermjo B, etal. Effective measurement of network vulnerability under random and intentional attacks[J]. Journal of Mathematical Modeling and Algorithm, 2005, 4(3): 307-316

[3] Hall D L, Linas J.Handbook of multisensor data fusion[M].Washington DC,NY:CRC Press, 2001.

[4] PEREIRA R A M, RIBEIRO R A. Aggregation with generalized mixture operators using weighting functions[J]. Fuzzy Sets and Systems, 137(2003)43-58.

[5] Faloutsos M, Faloutsos P, Faloutsos C.Computer Communications Review, 1999, 2: 251

[6] Barabási A L, AlbertR. Science, 1999, 286: 509

[7] Barabási A L, Albert R, Jeong H. Physica A, 1999, 272: 173

[8] NEWMAN M E J , WATTS D J . Renormalization group analysis of the small-world network model[J]. Phys Lett A, 1999, 263: 341-346

[9] Barabasi A L, Albert R. Emergence of Scaling in Random Networks[J]. Science, 1999, 286(3): 509-512

[10] Curry, G.R. Radar System Performance Modeling, Artech House, Norwood, 2001.

[11] Ahuja G.2000. Collaboration networks, structural holes and innovation: A longitudinal study[J]. Administrative Science Quarterly, 45:425 455. 